\title{
PATRIMÔNIO DIGITAL E INFORMAÇÃO: POLÍTICA, CULTURA E DIVERSIDADE
}

\author{
DIGITAL HERITAGE AND INFORMATION: POLITICS, \\ CULTURE AND DIVERSITY
}

\author{
Lídia Eugenia Cavalcante - lidia@ufc.br \\ Doutora em Educação \\ Professora do Departamento de Ciências da Informação \\ Universidade Federal do Ceará
}

\begin{abstract}
Resumo
Este texto, que é parte da pesquisa de pós-doutorado em Ciências da Informação, realizada na École de Bibliothéconomie et des Sciences de l'Information (EBSI), da Université de Montréal - Canadá, versa sobre Informação, Memória Social, Cultura e Patrimônio Digital. Tem o objetivo de apresentar algumas reflexões sobre os desafios de salvaguarda e acesso ao patrimônio, em meio eletrônico, com ênfase nas questões culturais, econômicas e políticas que envolvem a temática. Toma como elemento inicial de reflexão o documento: "Carta da UNESCO sobre a Preservação do Patrimônio Digital" e sobre a "Memória do Mundo", amplamente divulgado na Internet, e que tem estimulado os diferentes países membros e instituições ao estabelecimento de políticas, estratégias, ações, programas, padrões, diretrizes e metodologias que assegurem a preservação e o acesso à memória e ao patrimônio mundial em ambiente virtual.
\end{abstract}

Palavras-Chave: Preservação. Memória Social. Patrimônio Digital. Ciência da Informação. Cultura e Política.

\section{INTRODUÇÃO}

... e já se vai o tempo em que o tempo não importava. O homem moderno não se dedica mais ao que não pode ser abreviado.

Walter Benjamin

É emocionante para um professor/pesquisador de História do Livro e das Bibliotecas, conectar-se ao site da Fundação Biblioteca Nacional (FBN), durante uma aula, depararse com acervos de grandes tesouros nacionais e internacionais do registro da produção do conhecimento humano, e apresentar para os alunos um documento produzido em 
tempos longínquos. Obras raras, originais da iconografia, da música ou fascinantes manuscritos, já digitalizados e postos à disposição de um público cada vez maior. São documentos fundamentais para conhecer como se processou, ao longo dos séculos, a trajetória humana registrada em diferentes aspectos: histórico, artístico, ideológico, político ou religioso, por exemplo.

Acessar a primeira edição da Arte da grammatica da lingoa mais usada na costa do Brasil, de 1595, por Padre Anchieta, ou a Bíblia de Mogúncia, escrita em latim e impressa em 1462, significa a possibilidade de tornar acessível, mesmo que de modo virtual e representativo, uma parte do patrimônio histórico-cultural brasileiro, bem como de outros lugares do mundo, para pesquisadores, historiadores, educadores, estudantes e demais interessados. É uma forma de coletivizar e tornar conhecido, acervos que antes se destinavam exclusivamente à preservação, e não ao acesso, devido à fragilidade e degradação física, geradas por séculos de existência. Estamos diante de um admirável instrumento de pesquisa, educativo ou mesmo de pura curiosidade, fascinante, do ponto de vista histórico e social, e o uso da tecnologia pode garantir acesso, sem risco de roubo, depredação ou danificação dos originais, a maioria guardada em cofres.

A digitalização desses documentos e a criação de um patrimônio digital, além do fascínio que exerce e da justificação social, histórica e cultural que apresenta necessita, entretanto, de um importante trabalho de reflexão, que possa ir além de leitura linear ocasionada pela euforia do presente. Reflexão que inicia com a constatação de tratar-se de uma representação do real, especialmente quando nos referimos a documentos históricos, (representativos de fenômenos sociais ou testemunhas de uma era), produzidos no passado, em suportes físicos e atualmente digitalizados, que não poderão efetivamente (pelo menos no presente) substituir a obra em si, em sua materialidade, mesmo que se configurem em reproduções de alta qualidade e de perfeição completamente idênticas aos originais, de uma fidelidade impressionante. Para Desvallées, (2001, p.18), "Passou-se ao mesmo tempo do suporte papel para o suporte eletrônico e da contemplação individual ou colectiva, mas monotópica, à contemplação universal e mundial."

Por conseguinte, questões de preciosa relevância vão sendo discutidas cotidianamente, considerando abordagens de caráter conceitual, político, formal, social, ético e econômico entre os pares. Neste debate, situamos a UNESCO como mediadora, tendo 
em vista o papel que exerce internacionalmente e as preocupações que levanta com relação às ações para salvaguardar a "memória do mundo", em muitos casos ameaçada. A UNESCO lançou, em 2003, documento sobre a "Preservação do Patrimônio Digital" visando à identificação de conceitos, estratégias, ações políticas e éticas, dentre outras propostas, para gerar um processo de discussão conjunta entre as nações. Também tem apoiado cotidianamente ações culturais, sociais e políticas, além de facilitar programas de digitalização de acervos em várias partes do mundo, o que a torna um dos agentes mais importantes e decisivos para o processo de patrimonialização digital, que tende a efetivar-se mundialmente.

Outro fator relevante nessas discussões refere-se à efemeridade inerente aos documentos produzidos diretamente em meio digital, muitas vezes de forma caótica e sem nenhuma preocupação com a preservação, o que pode afetar significativamente o futuro da memória de instituições, movimentos sociais, partidos políticos, associações e de comunidades entre outros.

Diante destas e de outras questões a serem abordadas acerca das relações entre memória, informação e patrimônio digital, é que esta pesquisa se constrói. O texto ora apresentado é um ensaio para traçar um panorama a partir da pesquisa de pós-doutorado realizada na École de Bibliothéconomie et des Sciences de l'Information (EBSI), da Université de Montreal - Canadá, que toma como referência o movimento mundial em torno da salvaguarda e acesso ao patrimônio digital, a partir da Carta da UNESCO (2003), amplamente divulgada na Internet, cujo objetivo principal é "assegurar a preservação e o acesso universal ao patrimônio documental mundial”.

Inicialmente, procuramos entrelaçar eventos históricos e conceitos relativos à questão patrimonial, já amplamente documentados e divulgados, que necessitam ser constantemente relembrados e discutidos, de modo a favorecer o debate e evitar os riscos do esquecimento tão comuns quando o assunto é memória, o que parece profundamente contraditório e complexo.

\section{A GÊNESE DE UMA NOVA FORMA DE PATRIMÔNIO?}

As conexões entre memória e informação ocorrem por meio de fortes mediações, que se constroem no cotidiano da sociedade e seus diversos grupamentos, quer sejam 
sociais, políticos, culturais e científicos. Juntos, esses grupos vão compondo uma herança enriquecida pelas experiências, tradições, produções e acontecimentos, que se estabelecem entre os sujeitos, compondo uma memória social, muitas vezes materializada e registrada em suportes físicos, que vão constituindo um patrimônio quer seja arquitetônico, artístico, histórico ou cultural, apenas para citar alguns.

O campo de estudos sobre memória social tem vivenciado significativas mudanças, ocasionadas por renovações, que se inscrevem por meio das transformações ocorridas entre os indivíduos e a cultura contemporânea, inseridas nos debates travados em diversas áreas do conhecimento. Redes vão se constituindo a partir das heranças que se transformam em legado à humanidade e à suas gerações. O que outrora parecia memória de um pequeno povoado, grupo social ou organizações, vai se transformando em "memória do mundo" cujo acesso se concretiza por meio de várias possibilidades e, atualmente, inclusive por meio digital. Com o advento da tecnologia, o estatuto do patrimônio adquire novo status e agrega valores e formatos, bem como nova problemática a ser estudada por pesquisadores, de modo interdisciplinar. Em muitos países, grupos de pesquisa, políticos e de trabalho vão se constituindo, muitos à distância, para facilitar o debate acerca da constituição de acervos digitais, com ênfase em discussões epistemológicas, éticas, práticas, políticas, estabelecimento de normas e ações, que visem a salvaguarda e a democratização desse patrimônio, cujas limitações ainda são destaques, especialmente no que se refere às barreiras relativas a diversidade cultural e lingüística e à exclusão digital, comuns em países da América Latina e da África.

São múltiplas as mudanças surgidas nas atuais formas de compreensão do que vem a ser caracterizado como patrimônio, quando o assunto é documento em meio digital. “... Nos encontramos indubitavelmente num ponto de virada do patrimônio [...] viragem tão importante quanto aquela que sucedeu há dois séculos quando a Europa, depois de tomar consciência do seu patrimônio cultural, passou da coleção privada ao museu público.” Desvallés (2001, p.2). No fecundo e controverso século XVIII, tornar público e democratizar o acesso a patrimônios culturais e à informação teve, portanto, importância capital. Ação fortalecida pela Revolução Francesa, pelo avanço do conhecimento influenciado por aqueles considerados cidadãos da República das Letras (BURKE, 2003, p. 26), dos enciclopedistas, membros de academias científicas e de 
gabinetes literários, que contribuíram efetivamente para que o conhecimento passasse da esfera privada para uma ação mais próxima do meio social, com destaque para os museus e bibliotecas.

Para Micoud, (2005, p.81), a constituição de um patrimônio deve passar, necessariamente, por um processo de patrimonialização. Isto é, fazer com que um bem seja considerado patrimônio a partir de critérios históricos, sociais, culturais, éticos, econômicos ou do direito, que garantam um valor representativo de um grupamento humano e de sua memória coletiva, cuja salvaguarda, ainda que simbólica, favoreça a preservação e o acesso a gerações futuras. Segundo Micoud (2005), a atividade de patrimonialização é a perpetuação de uma entidade social no tempo, como um legado das gerações precedentes. Este é um tempo de salvaguarda e não mais de conservação. Este último termo nos faz lembrar as bibliotecas medievais, cujo objetivo era conservar no sentido de manter longe do público seus valiosos tesouros, basicamente por dois motivos: o risco do acesso ao conhecimento e a fragilidade do suporte.

A noção de patrimônio, conseqüentemente a salvaguarda, tem sido amplamente alargada nos últimos trinta anos. Especificamente, podemos citar como data importante o ano de 1972, quando ocorreu a Convenção Sobre a Proteção do Patrimônio Mundial Cultural e Natural $^{1}$, realizada pela UNESCO, em Paris. Aquele evento visava garantir a salvaguarda e a conservação dos bens tangíveis mundiais, fundamentais para a manutenção do processo de construção histórica do homem e a herança da humanidade. Buscava também favorecer o equilíbrio entre cultura e natureza, categorias sempre isoladas das formas sociais de pensar o mundo. A responsabilidade das ações para esse fim ficaria a cargo dos países membros e da comunidade internacional. O debate político e cultural que se instaurara, a partir daquele evento, oficializou um movimento internacional, especificamente nascido na Europa, por ocasião principalmente das ações depredatórias ocorridas durante a primeira e a segunda guerras mundiais, quando importantes obras do patrimônio de museus, bibliotecas e arquivos foram transformados em despojos de guerra, como uma espécie de troféu aos vencedores.

Movimentos começaram a se fortalecer em prol da preservação da memória humana

1 UNESCO. Convenção para a Proteção do Patrimônio Mundial, Cultural e Natural. Disponível em : $<$ http://www.unesco.pt/pdfs/cultura/docs/3 Convencao_Protecao_Patrimonio.doc. $>$ Acesso em : 30 out. 2006 . 
(natural e cultural). Uma das grandes preocupações mundiais com a preservação do patrimônio se deve, entre outros motivos, à devastação causada por conflitos armados, a exemplo do que acontecera recentemente na guerra no Iraque e também no Afeganistão, ameaçando pequenos sítios arqueológicos, museus, bibliotecas e grandes obras arquitetônicas, bem como importantes patrimônios naturais da humanidade levando a uma significativa perda do patrimônio tanto histórico-cultural quanto natural.

Outros fatores também contribuem para a devastação, como: a questão educacional, o turismo predatório, o desconhecimento do valor histórico, a falta de políticas de valorização do patrimônio, o vandalismo, ou mesmo a falta ou inexistência de cooperação local, nacional ou internacional. Vale salientar que, dentre as principais medidas para a preservação e valorização patrimonial está o investimento em educação, conscientização e geração de políticas públicas, que garantam à sociedade participação e interesse no processo.

A Convenção da UNESCO de 1972 efetiva-se internacionalmente como a ação política inovadora mais importante de concretização de propostas para salvaguarda e proteção do patrimônio mundial, buscando promover uma forte relação entre natureza e cultura, tornando claro que ambas constituem o fundamento da vida humana na Terra, se alargamos o conceito de cultura para tudo aquilo que é produzido pelo homem e que instaura uma identidade constituída por criações ao longo de sua existência, capaz de conferir às novas gerações conhecimento, acumulação, memória e desenvolvimento.

Em novembro de 1989, em Paris, na 25a Sessão da Conferência Geral da UNESCO, a cultura tradicional e popular, e não exclusivamente os bens tangíveis, passa a se configurar como uma nova preocupação do quesito patrimonial, quando é então aprovado o texto Recomendação sobre a Salvaguarda da Cultura popular e Tradicional, considerando-a como parte do patrimônio universal da humanidade e um poderoso meio de aproximação entre os povos e grupos sociais existentes e de afirmação de identidade cultural. Leva também em consideração,

A importância social, econômica, cultural e política, de seu papel na história dos povos, assim como do lugar que ocupa na cultura contemporânea. Destacando a natureza específica e a importância da cultura tradicional e popular como parte integrante do patrimônio cultural e da cultura viva. ${ }^{2}$

2 UNESCO estabeleceu, em 1989, a Recomendação sobre a Salvaguarda da Cultura Tradicional e 
A cultura tradicional e popular, ao se constituir oficialmente como patrimônio da humanidade, dá lugar a uma importante decisão política para, efetivamente, tornar-se referência de identidade aos diferentes povos e suas manifestações e heranças, muitas vezes transmitidas apenas oralmente, como é o caso das tradições folclóricas brasileiras ou também de outros povos como na África, algumas correndo o risco de desaparecerem. Com o apoio da UNESCO, essas manifestações populares ganham força no cenário das políticas públicas nacionais e internacionais a partir de uma dinâmica que é característica da cultura e é a sua transmissão que poderá garantir às gerações futuras existência e permanência.

Para Fentress e Wickham(1992, p. 42), a memória é

[...] uma fonte de conhecimento. Isso significa que faz mais do que fornecer um conjunto de categorias através do qual, de um modo inconsciente, um grupo habita o seu meio; dá também ao grupo matéria de reflexão consciente. Isso significa que devemos situar os grupos em relação às suas próprias tradições, descobrindo como interpretam os seus 'fantasmas' e como os utilizam para fonte de conhecimento.

A memória ocorre no terreno das ambigüidades e complexidades, assim como se condiciona a uma hierarquia de poder, que percebemos no modo como é ela transmitida e conservada. São os mecanismos de transmissão que auxiliam, em grande medida, a conservação das imagens que temos do passado, capaz de legitimar a ordem social na qual se estabeleceu. Por conseguinte, emerge da noção de patrimônio cultural, tal qual se apresenta nas Recomendações da UNESCO de 1989, uma certa complexidade com as marcas da chamada globalização, fortalecidas na década de 1990, de ordem muitas vezes contraditória, quando aquele documento defende as identidades locais, as memórias orais, as danças e as manifestações folclóricas entre outras, como patrimônio da humanidade. Nesse caso, a salvaguarda se tornou indispensável e que, paralelamente, sobrepõe-se uma nova forma de patrimônio global, amplamente difundida, especialmente entre os países ricos e desenvolvidos tecnologicamente. Isto é, uma nova

Popular. Esse instrumento legal fornece elementos para a identificação, a preservação e a continuidade dessa forma de patrimônio, assim como de sua disseminação. UNESCO. Recomendação sobre a salvaguarda da cultura tradicional e popular. In: CONFERENCIA GERAL DA UNESCO, 25ª Reunião, $\begin{array}{lllllll}\text { Paris } & 15 & \text { de } & \text { novembro } & \text { Disponível } & \text { em:. }\end{array}$ http://www.unesco.org/culture/laws/paris/html_sp/page1.shtml. Acesso em: 30 out. 2006. 
forma de pensar o patrimônio cultural tem sido discutida como uma espécie de evolução da produção cultural humana representada em meios digitais.

A preocupação em preservar aquilo que se produz ou se transfere para o ciberespaço e pode ser considerado como patrimônio digital possui ainda muitas questões e poucas respostas. A área da Ciência da Informação, por exemplo, se manifesta para abrigar fortes discussões no centro dessas reflexões: como pensar a memória documental em um contexto de diversidade e complexidade, especialmente se considerarmos a ambiência de espaços geográfico, social e virtualmente interativos? Seria, pois, a memória digital excludente no contexto da democratização da informação?

Historiadores, Cientistas Sociais e da Ciência da Informação têm se colocado perante a uma questão profundamente necessária na atualidade: como pensar a preservação da memória e do patrimônio digital sem que acervos importantes que compõem a história da humanidade possam se perder no espaço virtual? Como trabalhar conceitualmente memória, documento e patrimônio e suas diferenciações entre o que é produzido e preservado em papel ou eletronicamente? Como desenvolver políticas de identificação daquilo que pode ser considerado patrimônio digital? Assim, o Manifesto da UNESCO sobre a Preservação da Memória Digital vem contribuir sobremaneira para a reflexão dessa temática. Isto é, como percebemos a memória e o patrimônio e sua relação com as questões tecnológicas, culturais e políticas de modo a garantir preservação e acesso em um espaço a ser pensado democraticamente.

A UNESCO, em 2003, em sua Conferência Geral, no que concerne a Declaração Universal sobre a Diversidade Cultural, por meio do programa Memória do Mundo, lança a Carta sobre a Preservação do Patrimônio Digital, evidenciado uma forte e necessária preocupação mundial com a preservação do patrimônio digital da humanidade, já que muitos documentos são produzidos unicamente em meio eletrônico e podem perder-se no tempo e no espaço, tanto pela efemeridade do suporte quanto pela falta de políticas de preservação. Trata-se de uma questão bem peculiar para o século XXI, tendo em vista que o universo informacional, em meio digital, tem se tornado mais dinâmico e produtivo, criando um novo legado histórico-cultural.

De acordo com a UNESCO (2003), o patrimônio digital constitui-se como um bem público e pode ser definido como: 
Recursos de conhecimento ou expressão humana, seja cultural, educacional, científico e administrativo, ou abrangendo a informação técnica, legal, médica e outros tipos de informação, criados digitalmente ou convertidos de sua forma analógica original à forma digital.

[...] incluem textos, bases de dados, imagens estáticas e com movimento, áudios, gráficos, softwares, e páginas $W e b$, entre uma ampla e crescente variedade de formatos. Eles geralmente são passageiros e requerem produção, manutenção e gerenciamento intencionais para serem preservados.

Muitos desses materiais são de valor e significância duradouros, e por isso constituem um patrimônio que deve ser protegido e preservado para as gerações atual e futura. Este patrimônio existe em qualquer língua, parte do mundo, e em qualquer área do conhecimento e expressão humanos. ${ }^{3}$

Diante dessas preocupações, há que se reconhecer a importância da memória e do patrimônio digital quanto às oportunidades de acesso, conhecimento, compartilhamento e preservação, gerando questão social da maior relevância que é a inclusão digital dos diferentes povos da Terra. Entretanto, também lidamos com um tema de caráter ético e político que necessita prudência, pois se trata de um desafio às comunidades políticas e científicas, diante da complexidade do momento histórico atual no campo informacional, cultural e tecnológico.

Para Mattelart (2002), “há um processo de amnésia que está em andamento” e é, segundo ele,

a recuperação da linguagem, a reconstrução de uma linguagem, a única forma de lutar contra o esvaziamento e o empobrecimento do nosso vocabulário quando falamos sobre o processo de integração das culturas e das sociedades diante de um conjunto mais importante e dito universal. ${ }^{4}$

A preocupação com a linguagem também se constitui como um dos grandes dilemas relacionados à integração entre as chamadas culturas dominantes e as pequenas nações, com relação aos elementos decisivos para o desenvolvimento de políticas de geração,

3 UNESCO. Minuta revisada da carta sobre preservação do patrimônio digital (anexo I). Disponível em:

$<\underline{\text { http://osi.unesco.org.br/arquivos/documentos/UNESCO anexoImemoriadigital.pdf. }>\text {. }}$ 4 Palestra proferida no painel "Como garantir as identidades culturais e proteger a criação artística da mercantilização?”. Fórum Social Mundial, Porto Alegre, 29 de janeiro de 2002. Divulgada na Internet. http://www.forumsocialmundial.org.br/txt/mattelart.asp 
preservação e acesso ao patrimônio digital.

Devemos reconhecer também a reivindicação da singularidade das culturas que se desenvolvem hoje num contexto muito contraditório: poderia ser o retorno às culturas singulares, poderia ser uma forma de pensar e repensar o universalismo, uma nova forma de universalismo, mas também poderia ser uma forma de reflexão sobre si mesmo. Esse é o grande desafio do século XXI. Espero que neste século XXI consigamos resolver o que o século XX não conseguiu. ${ }^{5}$

Para que ocorra uma possível universalização do patrimônio digital é preciso evitar o risco de pensar a cultura de forma globalizada ou uniforme, o que certamente poderia levar ao desaparecimento de pequenos patrimônios, de países pobres ou sem acesso à tecnologia, ou mesmo impossibilitados por razões econômicas, ideologias religiosas ou políticas, que defendem ou pregam a exclusão tecnológica de seus mecanismos informacionais. Há, portanto, diferenças entre universalização do patrimônio digital, sob o ponto de vista do acesso, e a difusão de uma cultura globalizada, com ênfase em documentos e acervos disponíveis especificamente em línguas de grande difusão internacional, correndo o risco do desaparecimento da diversidade cultural tão característica da raça humana.

Para o historiador contemporâneo Roger Chartier (2002, p. 15), inspirado nas leituras de Jorge Luis Borges, aquilo que define os seres humanos em sua humanidade é: "a memória, o nome, a diferença". O autor questiona sobre "como pensar a língua desse novo 'congresso do mundo' tal como é construído pela comunicação eletrônica?”. A questão posta por Chartier nos leva a evidenciar outra situação com relação à "Memória do Mundo", isto é, como preservar e disseminar essa nova forma de patrimônio humano que está sendo produzida ou representada, diante dos dilemas econômicos, religiosos, políticos e ideológicos que ora se apresentam?

De acordo com a UNESCO, “a língua constitui o vetor fundamental de comunicação entre os indivíduos e representa uma parte essencial do patrimônio cultural". ${ }^{6}$ Nesse sentido, as políticas que visam à construção de um patrimônio digital deve fazer uso das tecnologias para promover o acesso cultural e lingüístico, também no sentido de

5 Id. Ibid.

6 UNESCO. Multiculturalismo dans le cyberespace. Disponivel em:

$<$ http://portal.unesco.org/ci/fr/ev.p $>$. 
preservar as línguas e culturas em risco de extinção, especialmente no continente africano, cuja fragilidade se apresenta de modo mais devastador.

Muitas são as iniciativas internacionais que se propõe a pensar a sociedade sob o ponto de vista da diversidade cultural, da política e do direito ao acesso à informação e ao patrimônio digital, de modo democrático, na tentativa de reduzir as disparidades sociais e tecnológicas existentes, com a finalidade de garantir a difusão do conhecimento e da cultura local, de modo global, garantindo a diversidade de línguas, culturas e desenvolvimento sustentável do patrimônio, quer seja natural ou social.

Entre os principais eventos internacionais e documentos produzidos acerca dessa temática são destaques: Iniciativa de Budapeste para Acesso Aberto, realizada em fevereiro de 2002; Carta da UNESCO sobre a conservação do patrimônio digital, em 2003; Declaração de Bethesda para edição em livre acesso, em junho de 2003; Declaração de Berlim sobre o Livre Acesso ao Conhecimento em Ciências Exatas, Ciências da Vida, Ciências Humanas e Sociais, em outubro de 2003; Declaração da IFLA sobre o livre acesso a literatura científica e aos documentos de pesquisa, em dezembro de 2003 e Carta do Grupo de Ouagadougou, setembro de 2005. 
Especificamente, no que se refere às questões relativas ao patrimônio francofone africano, no período de 26 de setembro a primeiro de outubro de 2005, ocorreu o seminário intitulado Développement durable et bibliothèques : l'information numérique enjeu de la diffusion de la connaissance et des savoirs, realizado em Ouagadougou (Burkina Faso), na África, organizado pelo 1'Institut Francophone des Nouvelles Technologies de l'Information et de la Formation (INTIF) em colaboração com o l'Institut Panafricain pour le Développement - Afrique de l'Ouest et Sahel (IPDAOS). O evento buscou reunir profissionais de bibliotecas e outras áreas ligadas ao desenvolvimento tecnológico e informação, dos países de língua francesa, especialmente da África, para discutir questões relativas ao desenvolvimento de bibliotecas digitais e produção de documentos eletrônicos, conservação, difusão, acessibilidade e gestão. Segundo o documento produzido pelo evento, o termo ecologia documentária permite precisar os objetivos relativos a adequação de ações tradicionais das bibliotecas e o seu papel na sociedade atual, no que se refere ao desenvolvimento durável, de produção, preservação, gestão e acesso para as gerações atuais, preservando as condições de utilização que beneficiaram às futuras gerações. (Ouagadougou, 2005) ${ }^{7}$.

No Brasil, há também iniciativas sobre as questões relativas ao patrimônio digital, a exemplo do Conselho Nacional de Arquivos - Conarq, que a partir da Carta da UNESCO, lançou em 2004 a Carta para a Preservação do Patrimônio Arquivístico Digital - Preservar para Garantir o Acesso. Ações observadas também no trabalho da Fundação Biblioteca Nacional, de grupos de pesquisa e/ou acadêmicos em universidades, bibliotecas, arquivos e museus, que ampliam os debates sobre políticas de preservação, salvaguarda e acesso ao patrimônio digital.

Por ocasião da pesquisa de pós-doutorado na Université de Montreal - Quebec Canadá, interessa-nos, no presente, estudar as políticas e ações voltadas para a preservação do patrimônio digital em instituições canadenses, responsáveis por esse

7 SEMINAIRES INTIF/IPD-AOS : OUAGADOUGOU, 26 septembre $-1^{\circ}$ Octobre 2005 "Développement durable et bibliothèques : l'information numérique enjeu de la diffusion de la connaissance et des savoirs". Disponivel em : < $\underline{\text { http://linux.univ-lyon2.fr/Ouagadougou-2005/>. }}$. 
trabalho de salvaguarda da memória nacional, são elas: Bibliotecas e Arquivos Canadá / Biblioteca Nacional do Canadá (BNC), que desde 1990, como parte de sua gestão de coleções já incluía políticas de aquisição e conservação de publicações eletrônicas em rede. A Rede Canadense de Informação sobre o Patrimônio, que se volta particularmente para os museus públicos ou sem fins lucrativos e outros organismos de valorização do patrimônio nacional, e ainda a Biblioteca Nacional do Quebec, por meio do acervo histórico-cultural digitalizado, que inclui cartas postais, revistas e jornais entre outros documentos importantes para a história do Canadá.

De um modo geral, as organizações que pensam as políticas de salvaguarda e acesso ao patrimônio digital, têm como preocupação dar visibilidade às questões sociais, culturais e democráticas de tornar acessível o que é considerado bem comum da humanidade, e que a prática da digitalização pode transformar-se em indispensável aliada nesse processo. Porém, é importante que políticas públicas sejam criadas e adotadas, especialmente para garantir os recursos financeiros e humanos necessários a esse domínio, bem como fortalecer as ações desenvolvidas por agências nãogovernamentais.

Com o apoio da UNESCO, notadamente a partir da adoção da Carta sobre a Conservação do Patrimônio Digital (2003), organizações não governamentais ou sem fins lucrativos, optaram por desenvolver estratégias de preservação de seu patrimônio em meio digital, para evitar os riscos de perdas irreparáveis de documentos produzidos unicamente em meio eletrônico ou em outros suportes, posteriormente digitalizados. Muitas dessas organizações eram identificadas por um certo conservadorismo de suas práticas, inclusive com relação à gestão de seus documentos arquivísticos. Em alguns casos, por questões políticas, a exemplo de sindicatos e partidos.

São memórias da história local, nacional ou internacional que constituem valiosas coleções e fontes de informação indispensáveis para pensar historicamente o movimento sócio-cultural e político. Memórias militantes, movimentos populares, história oral, história de vida, fotografias, imagens, arquivos de eventos, documentos jurídicos, discursos e entrevistas, que servirão às novas gerações, principalmente em meio educativo e para facilitar a pesquisa científica de diferentes áreas do conhecimento. Para Lévy (2005, p. 22), 
De maneira análoga, diversos sistemas de registro e de transmissão (tradição oral, escrita, registro audiovisual, redes digitais) constroem ritmos, velocidades ou qualidades de histórias diferentes. Cada novo agenciamento, cada 'máquina' tecnossocial acrescenta um espaçotempo, uma cartografia especial, uma música singular a uma espécie de trama elástica e complicada em que as extensões se recobrem, se deformam e se conectam, em que as durações se opõem, interferem e se respondem. A multiplicação contemporânea dos espaços faz de nós nômades de um novo estilo: em vez de seguirmos linhas de errância e de migração dentro de uma extensão dada, saltamos de uma rede a outra, de um sistema de proximidade ao seguinte. Os espaços se metamorfoseiam e se bifurcam nossos pés, forçando-nos à heterogênese.

Observa-se também a emergência de novos movimentos sociais e políticos à distância, que se organizam em prol de objetivos comuns, quer seja no Brasil, em países da África, no Canadá ou na França, por exemplo. Assim, surgem formas de engajamento cuja documentação e correspondências entre os militantes e líderes vão constituindo um patrimônio produzido unicamente em meio eletrônico e divulgado pela Internet. O que requer todo um trabalho de gestão, preservação e acesso. Trata-se, pois, de movimentos promovidos sem panfletos ou adesivos - tão característicos e emblemáticos de tempos de outrora, cuja divulgação, assinatura e adesão ocorrem exclusivamente no ciberespaço, eletronicamente e em listas de discussões. Independente da forma como esses documentos são gerados ou difundidos, há uma memória produzida e acumulada, que precisa ser preservada e o acesso garantido. São fontes de informação desterritorializadas, cuja idéia de transmissão se dá por meio de redes, o que assegura acesso a um número maior de usuários e, teoricamente, liberdade de apropriação por meio do livre acesso.

Além do acesso à informação, no caso dos movimentos sociais e culturais criados e difundidos no ciberespaço, o patrimônio digital poderá conferir aos indivíduos partícipes de tais movimentos, a possibilidade de desenvolver um processo de igualdade e democracia, caso isso se transforme em prática política e ética pela distribuição clara de competências, difusão de objetivos e de recursos financeiros obtidos, bem como das fontes de obtenção. Vale salientar, que essas ações não estão imunes a processos jurídicos e do direito, não menos importantes. Porém, essa categoria não se constitui parte integrante desta abordagem.

O estatuto do patrimônio, ao se tornar cada vez mais heterogêneo em suas abordagens e 
categorias, com a emergência do patrimônio digital adquire cada vez mais um espírito de coletividade e bem social em meio a uma abrangência global. Entretanto, além da grandeza tecnológica que pretende torná-lo democrático, há que se pensar verdadeiramente na institucionalização de políticas públicas para valorização das diferentes formas de manifestações humanas e memória social, que privilegiem as riquezas locais, nacionais e internacionais, sejam elas lingüísticas, folclóricas, artísticas, naturais, tecnológicas ou políticas, manifestas ou ainda adormecidas, para evitar o risco do desaparecimento, da dominação ou do cárcere que ainda cerceia o direito à informação.

\section{CONCLUSÕES}

Em várias definições sobre o conceito de patrimônio (tratando-se especificamente de patrimônio coletivo), temos como ponto em comum termos como estocagem, fonte de acumulação e criação de valor, constituição de coleções, informação, preservação, bens de natureza coletiva, cultural, histórica, social, econômica ou política, que garantem lugar na sociedade, no passado, presente ou futuro, permitindo a constituição de identidades e dinâmica social. Destacamos também o fato de que um patrimônio documental digital deve garantir democraticamente a diversidade de línguas e culturas, buscando preservar identidades e diversidades para garantir a salvaguarda de memórias nitidamente frágeis.

As sociedades recordam aquilo que a elas interessam. Buscam uma reconstrução histórica que preserve o vivido, os seus heróis e conquistas. Porém, que essas recordações não escravizem suas mentes, daí a afirmação de que memórias, antes de serem sociais, elas são pessoais, podendo, em alguns casos, ser silenciadas, mas dificilmente oprimidas.

É importante que políticas e programas de cooperação internacionais sejam amplamente desenvolvidos e difundidos, considerando o fato de que há povos e nações cujo processo de desenvolvimento tecnológico se apresenta com pouco ou nenhum investimento. Tem-se observado o envolvimento de organizações culturais, sociais e científicas nesse processo, a exemplo das bibliotecas, museus e arquivos nacionais de diferentes países. Demonstra, que a área informacional e seus profissionais estão atentos e discutindo 
questões relativas ao patrimônio digital, pautadas em trabalho de atualização tecnológico, conceitual, social e político, diante das novas práticas e dinâmicas da constituição de fontes de informação, coleções documentárias e do processo de patrimonialização.

O patrimônio digital é, sobretudo, uma construção social, na qual os seres humanos e suas ações no tempo e no espaço constituem a grande riqueza documentada. Não representa algo acabado, é uma estrutura que vai sendo montada por grandes ou pequenos públicos. Paradoxalmente, trata-se de uma cultura dita globalizada, ao mesmo tempo em que se busca o reconhecimento da cultura de pequenos grupos, o compartilhamento e a troca de heranças e línguas em vias de desaparecimento em meio a um processo de virtualização e subjetividade cada vez maiores.

A salvaguarda, acesso e difusão da memória social em meio digital representam grande possibilidade de democratização da informação, assunto amplamente discutido em meios acadêmicos e sociais. É um processo que não inclui apenas a estocagem, mas toda a dinâmica de produção do conhecimento, partilha e transmissão. Trata-se, pois de evocar, além do discurso, a ação. É um trabalho de investimento, poderíamos dizer de sacralização e legitimidade.

\section{REFERÊNCIAS}

BARRÈRE, Chistian et al. (editeurs). Réinventar le patrimoine: de la culture à l'économie, une nouvelle pensée du patrimoine. Paris: L'Harmattan, 2005.

BOUTIER, Jean; JULIA, Dominique. Passados recompostos: campos e canteiros da história. Rio de Janeiro: EUFRJ/FGV, 1998.

BRASIL. Ministério da Cultura. Fundacão Biblioteca Nacional. Disponível em :

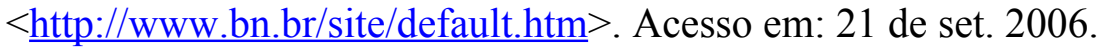

BURKE, Peter. Uma História social do conhecimento: de Gutenberg a Diderot. Rio de Janeiro: Jorge Zahar, 2003.

CANADA. Bibliotheque et Archives Canada. Introdution aux technologies et aux problemes de la numerization. Disponível em :

$<$ http://www.collectionscanada.ca/9/1>. Acesso em : 27 out. 2006.

. Iniciative canadienne sur les bibliotheques numeriques. Disponivel em :

$<$ http://nlc-bnc.ca/cidl. $>$. Acesso em : 27 out. 2006. 
CASTELS, Manuel. A Galáxia da internet: reflexões sobre a internet, os negócios e a sociedade. Rio de Janeiro: Jorge Zahar, 2003.

A Sociedade em rede. São Paulo: Paz e Terra, 2000.

CERTEAU, Michael. A Invenção do cotidiano: artes do fazer. Petrópolis: Vozes, 1996.

CHARTIER, Roger. Línguas e leituras no mundo digital. In.: CHARTIER, Roger. Os Desafios da escrita. São Paulo: UNESP, 2002.

CONSEIL D`ANALYSE ÉCONOMIQUE. La Société de I'information. Paris: La Documentation Française, 2004.

DESVALLÉES, André. Que futuro para os museus e para o patrimônio cultural na aurora do terceiro milênio? In: ENCONTRO APOM, novembro de 2001, Casa da Eletricidade, Funchal. [Conferência]. Tradução de João Carlos Brigola - Universidade de Évola]. Publicada in Lugar em Aberto, Revista da APOM, n.1, p. 46-74, out. 2003.

FENTRESS, Jamiesmn; WICKHAM, Chis. Memorial social: novas perspectivas sobre o passado. Lisboa: Teorema, 1992.

FIAB/IFLA. Disponível em:

$<$ http://bibliodoc.francophonie.org/article.php3?id_article=197>. Acesso em : 30 out. 2006 .

JEUDY, Henri-Pierre. Mémoires du social. Paris : Presses Universitaire, 1986.

LEVY, Pierre. Cibercultura. Rio de Janeiro: Editora 34, 1999. 2002.

Cyberdémocratie: essai de philosophie politique. Paris : Éditions Odile Jacob,

As tecnologias da inteligência: o futuro do pensamento na era da informática.

Rio de Janeiro: Editora 34, 1993.

O Que é virtual? São Paulo: Editora 34, 2005.

MAFFESOLI, Michel. La Transfiguration du político : la tribalization du monde. Paris : Bernand Grasset, 1992.

MARCUSCHI, Luiz Antônio; XAVIER, Antônio Carlos. Hipertexto e gêneros digitais: novas formas de construção de sentido. Rio de Janeiro: Lucerna, 2005.

MATTELART, Armand. A Utopia informacional. Conferência proferida no Colóquio Sociedade da Informação: novos paradigmas para as bibliotecas. Rio de Janeiro, maio 2005.

Como garantir as identidades culturais e proteger a criação artística da 
mercantilização?'[Conferência]. Fórum Social Mundial, Porto Alegre, 29 de janeiro de 2002. Disponível em: http://www.forumsocialmundial.org.br/txt/mattelart.asp

MENES, Cândido (Org.). Representação e complexidade. Rio de Janeiro: Garamond, 2003.

NAMER, Gerard. Mémoire et société. Paris: Méridiens Klincksieck, 1987.

RESEAU canadien d'Information sur le Patrimoine (RCIP). Orientation strategique 2003-2005. Disponivel em :

$<$ http://www.chin.gc.ca/Francais/Pdf/Description_Rcip/orientation strategique.pdf $>$

Acesso em : 30 out. 2006.

RODES, Jean-Michel ; PIEJUT, Genevieve ; PLAS, Emmanuèle. La Mémoire de la société de I'Information. Paris: UNESCO, 2003.

SEMINAIRES INTIF/IPD-AOS : OUAGADOUGOU, 26 septembre - $1^{\circ}$ Octobre 2005 "Développement durable et bibliothèques : l'information numérique enjeu de la diffusion de la connaissance et des savoirs". Disponivel em : $<$ http://linux.univlyon2.fr/Ouagadougou-2005/>. Acesso em: 30 out. 2006.

UNESCO. Manifesto para a Preservação Digital: proposta submetida pela comissão nacional da UNESCO dos países baixos, apresentada à Conferência Geral da UNESCO e aprovada para inclusão no Programa para 2002-2003. Disponível em:

$<$ http://www.bn.pt/agenda/manifesto unesco.html $>$ Acesso em: 19 maio, 2005.

UNESCO. Minuta revisada da carta sobre preservação do patrimônio digital (anexo I). Disponivel em:

$<\underline{\text { http://osi.unesco.org.br/arquivos/documentos/UNESCO anexoImemoriadigital.pdf. }>\text {. }}$ Acesso em: 19 maio, 2005.

UNESCO. Charte de L'UNESCO sur la conservation du patrimoine numerique. Disponível: $<$ http://portal.unesco.org/ci/fr/ev.php $>$. Acesso em: 21 set. 2006.

UNESCO. Convenção para a Proteç̧ão do Património Mundial, Cultural e Natural. Disponivel em :

$<\underline{\text { http://www.unesco.pt/pdfs/cultura/docs/3 Convencao_Protecao Patrimonio.doc. }}>$ Acesso em : 30 out. 2006.

UNESCO. Textos fundamentais da Convecao do Patrimonio mundial 1972. Disponivel em : $<$ http://whc.unesco.org/documents/publi_basictexts_pt.pdf. $>$. Acesso em : 30 out. 2006 .

UNESCO. Recomendação sobre a salvaguarda da cultura tradicional e popular. In: CONFERÊNCIA GERAL DA UNESCO, 25a. Reunião, Paris 15 de novembro de 1989. [Anais...]. Disponivel em: $<$ http://www.unesco.pt/cgibin/cultura/temas/cul tema.php?t=9. $>$. Acesso em: 30 out. 2006. 
UNESCO. Multiculturalismo dans le cyberespace. Disponivel em: $<$ http://portal.unesco.org/ci/fr/ev.p $>$. Acesso em: 30 out. 2006.

\begin{abstract}
This text is part of the post-doctoral research in Information Science, performed at the École de Bibliothéconomie et des Sciences de l'Information (EBSI), at Université de Montréal - Canada. The following areas are discussed: Information, Social Memory, Culture and Digital Heritage. Some reflections are presented concerning the challenges of heritage safeguard and access, with emphasis on the related cultural, economical and political questions. The following document is taken as an initial element for reflection: "UNESCO Charter on the Preservation of the Digital Heritage" and on the "World Memory". This document, widely disseminated on the Internet, has stimulated the different member countries and institutions in the establishment of politics, strategies, action, programs, patterns, directives and methodologies to ensure the preservation and access to the world memory and heritage in the virtual environment.
\end{abstract}

KEYWORDS: Preservation. Social Memory. Digital Heritage. Information Science. Culture. Politics.

Originais recebidos em 07/11/2006

Texto aprovado em 15/03/2007 